\title{
Octreotide therapy in meningiomas: in vitro study, clinical correlation, and literature review
}

\author{
Thomas Graillon, MD, PhD, 1,2 David Romano, PhD, ${ }^{1}$ Céline Defilles, PhD, ${ }^{1}$ \\ Alexandru Saveanu, MD, PhD, ${ }^{1}$ Amira Mohamed, PhD, ${ }^{1}$ Dominique Figarella-Branger, MD, PhD, ${ }^{4}$ \\ Pierre-Hugues Roche, MD, ${ }^{3}$ Stéphane Fuentes, MD, ${ }^{2}$ Olivier Chinot, MD, PhD, ${ }^{5}$ Henry Dufour, MD, ${ }^{2}$ \\ and Anne Barlier, MD, $\mathrm{PhD}^{1}$
}

\begin{abstract}
${ }^{1}$ Aix-Marseille Université, CNRS, CRN2M, UMR 7286; Departments of ${ }^{2}$ Neurosurgery, ${ }^{4}$ Pathology and Brain Pathology, and ${ }^{5}$ Neuro-oncology, Hopital La Timone, AP-HM; and ${ }^{3}$ Department of Neurosurgery, Hopital Nord, AP-HM, Marseille, France
\end{abstract}

\begin{abstract}
OBJECTIVE Meningiomas express somatostatin receptor subtype 2 (SST2), which is targeted by the somatostatin analog octreotide. However, to date, using somatostatin analog therapy for the treatment of these tumors in clinical practice has been debated. This study aims to clarify the in vitro effects of octreotide on meningiomas for precise clinical applications.
\end{abstract}

METHODS The effects of octreotide were analyzed in a large series of 80 meningiomas, including 31 World Health Organization (WHO) Grade II and 4 WHO Grade III tumors, using fresh primary cell cultures to study the impact on cell viability, apoptosis, and signal transduction pathways.

RESULTS SST2 mRNA was detected in $100 \%$ of the tested meningiomas at levels similar to those observed in other SST2-expressing tumors, neuroendocrine tumors, or pituitary adenomas. Octreotide significantly decreased cell proliferation in $88 \%$ of meningiomas but did not induce cell death. On average, cell proliferation was more inhibited in the meningioma group expressing a high level of SST2 than in the low-SST2 group. Moreover, octreotide response was positively correlated to the level of merlin protein and inversely correlated to the level of phosphorylated p70-S6 kinase, a downstream effector of the PI3K/Akt/mammalian target of rapamycin (mTOR) pathway. Octreotide inhibited Akt phosphorylation and activated tyrosine phosphatase without impacting the extracellular regulated kinase (ERK) pathway.

CONCLUSIONS Octreotide acts exclusively as an antiproliferative agent and does not promote apoptosis in meningioma in vitro. Therefore, in vivo, octreotide is likely to limit tumor growth rather than induce tumor shrinkage. A metaanalysis of the literature reveals an interest in octreotide for the treatment of WHO Grade I tumors, particularly those in the skull base for which the 6-month progression-free survival level reached 92\%. Moreover, somatostatin analogs, which are well-tolerated drugs, could be of interest for use as co-targeting therapies for aggressive meningiomas.

https://thejns.org/doi/abs/10.3171/2016.8.JNS16995

KEY WORDS meningioma; therapy; octreotide; somatostatin; merlin; SST2

$\mathrm{S}$ URGERY is the primary course of treatment for patients with meningioma, and radiotherapy is used when tumors are inoperable. As of now, there is no consensus in favor of chemotherapy; ${ }^{9}$ hence, it is rarely used in these patients' care.

Meningiomas express somatostatin receptor (SST) subtype 2 (SST2). ${ }^{14,15,43}$ This molecular characteristic is targeted in clinical practice when performing SPECT imaging (with radiolabeled octreotide) for the differential diagnosis of skull base tumors. ${ }^{30}$

Octreotide and lanreotide, both SST2 agonists, are pivotal therapeutic drugs for the treatment of somatotroph adenomas and gastroenteropancreatic neuroendocrine tumors (GEP-NETs), which are slow-growing tumors similar to meningiomas. These somatostatin analogs are used not only to suppress hormonal hypersecretion but also to

ABBREVIATIONS $\beta$ Gus = $\beta$-glucuronidase; $B$ rdU = bromodeoxyuridine; $E R K=$ extracellular regulated kinase; GEP-NET = gastroenteropancreatic neuroendocrine tumor; $\mathrm{mTOR}=$ mammalian target of rapamycin; $\mathrm{PBS}=$ phosphate-buffered saline; $\mathrm{PCR}=$ polymerase chain reaction; $\mathrm{PFS} 6=6$-month progression-free survival; SST = somatostatin receptor; SST2 = SST subtype 2; VEGF = vascular endothelial growth factor; WHO = World Health Organization .

SUBMITTED April 18, 2016. ACCEPTED August 5, 2016.

INCLUDE WHEN CITING Published online December 16, 2016; DOI: 10.3171/2016.8.JNS16995. 
control tumor growth. However, in meningiomas, the use of somatostatin analogs remains incidental.

Data from preclinical studies in numerous models have provided evidence for direct and indirect mechanisms by which somatostatin analogs exert antitumor effects. ${ }^{7} \mathrm{Di}-$ rect antitumor activity is mediated through the SST expressed in tumor cells and results from blocking cell division or inducing apoptosis, depending on the SST subtype and cell type. SST2 prevents cell growth by activating specific tyrosine phosphatases (SHP1, SHP2) and inhibiting the Ras/extracellular regulated kinase (ERK) and PI3K/Akt pathways, leading to the induction of cyclindependent kinase inhibitors and cell cycle arrest. ${ }^{16,37}$

Somatostatin analogs also exert numerous indirect antitumor effects, including 1) inhibition of growth factors and hormone secretion that drive tumor growth; 2) induction of antiangiogenic effects that reduce tumor blood flow, particularly by inhibiting vascular endothelial growth factor (VEGF) secretion; and 3) promotion of immunomodulatory effects to stimulate the body's natural antitumor mechanism. ${ }^{37}$

The somatostatin analogs have demonstrated antineoplastic activities in slow-growing neuroendocrine tumors and have good tolerability and safety profiles. Given these characteristics, they are attractive candidates for the treatment of patients with meningioma, particularly when longterm treatment is required. Some clinical studies have analyzed octreotide efficacy in patients with meningioma, yet their conclusions remain disputed and are sometimes undefined..$^{10,17,18,21,23,38,40,42,45}$ Moreover, the results of octreotide treatment in meningioma cells in vitro have been contradictory. ${ }^{4,26}$ Therefore, should we reject octreotide for meningioma therapy?

To clarify the direct antitumor effects of octreotide, we conducted an in vitro study using a large set of human meningiomas that included all histological subtypes and World Health Organization (WHO) Grade I, II, and III tumors. Moreover, we analyzed the signal transduction pathways triggered by octreotide and correlated the inhibition of cell proliferation to cellular markers. We also performed a meta-analytic review of all clinical data from the literature.

\section{Methods \\ Materials} AG.

Octreotide was obtained from Novartis International

\section{Primary Cell Culture of Fresh Human Meningiomas}

The study was performed on human meningiomas from 80 patients (Supplementary Table). The WHO grade (using 2007 criteria) for each tumor was determined by neuropathological review: 45 WHO Grade I tumors, 31 WHO Grade II , and 4 WHO Grade III. The present study was approved by the ethics committee of Aix-Marseille University and was conducted after obtaining informed consent from each patient. Briefly, freshly harvested tumor fragments were minced into small pieces $\left(<1 \mathrm{~mm}^{3}\right)$ and disaggregated into single cells by exposure to $0.37 \%$ type I collagenase (ThermoFisher Scientific Inc.) for 2 hours. Cells were resuspended in complete medium (1:1 ratio of DMEM high glucose $[4.5 \mathrm{~g} / \mathrm{L}]$ and F12 media, supplemented with $10 \%$ fetal bovine serum and $100 \mathrm{U} / \mathrm{ml}$ each of penicillin, streptomycin, and glutamine). ${ }^{20,36}$ The experiments were performed within the first 2 weeks after surgery and before the third subculture. Throughout this time period, the tumor cells in primary culture maintained their SST2 expression levels and their response to octreotide (Fig. 1) ${ }^{20}$ Experiments were performed on randomly selected tumors based on the quantity of tumor cells available after tumor dissociation (Supplementary Table).

\section{Cell Viability}

Cell viability was assessed by luminescent cell viability assay (Cell Titer-Glo, Promega Corp.) performed in triplicate on 24 -well plates containing $2 \times 10^{4}$ meningioma cells per well. Twenty-four hours after seeding, the cells were incubated in low-serum media (5\%) and treated with octreotide $\left(10^{-10}\right.$ to $\left.10^{-8} \mathrm{M}\right)$ for 3 days. All cell viability studies were performed on Day 3 because the cells were still proliferating and had not yet reached confluence. Cell viability results in treated versus untreated cells were expressed as a mean percent of the control. Direct cell counting was also performed on 3 tumors using a Scepter Automated Cell Counter (EMD Millipore Corp.).

\section{BrdU Incorporation Assay}

A total of $4 \times 10^{3}$ cells were seeded into each well of a 96-well plate. After 24 hours, cells were incubated in low-serum media and treated with octreotide $\left(10^{-9} \mathrm{M}\right)$ for 2 days. On the 3rd day, bromodeoxyuridine (BrdU) was added to a final concentration of $1 \mu \mathrm{M}$. After incubation of the cells for 16 hours, DNA synthesis was assayed using the Cell Proliferation ELISA BrdU Kit (Roche Diagnostics), and newly synthesized BrdU-DNA was determined using a microplate reader (Berthold Technologies).

\section{TUNEL Assay}

DNA fragmentation was detected by TUNEL using the ApopTag Red In Situ Apoptosis Detection Kit (EMD Millipore Corp.). A $10^{-8} \mathrm{M}$ dose of octreotide and a $10^{-10}$ $\mathrm{M}$ dose of staurosporine (Sigma Aldrich; positive control) were applied to meningioma cells that were previously seeded on 14-mm cover glass. After 2 days, the cells were fixed with paraformaldehyde for 15 minutes. Each experimental condition was assayed in quadruplicate. Apoptotic cells were then viewed and scored manually using a Leica/Leitz DMRB microscope with a PL Fluotar $\times 100$ objective. The percentage of apoptotic cells was evaluated based on > 2000 counted cells in 70-160 successive fields.

\section{Determination of Caspase Activity}

The activity of caspase- 3 and -7 was measured by luminescent Caspase-Glo assay (Promega Corp.). Twentyfour hours after seeding $2 \times 10^{4}$ meningioma cells into each well of a 24-well plate, the cells were incubated in low-serum media $(5 \%)$ and then treated with octreotide $\left(10^{-8} \mathrm{M}\right)$ for 3 days. The assay was performed in triplicate. Results were expressed as a mean percentage of caspase activity in treated versus untreated cells. 


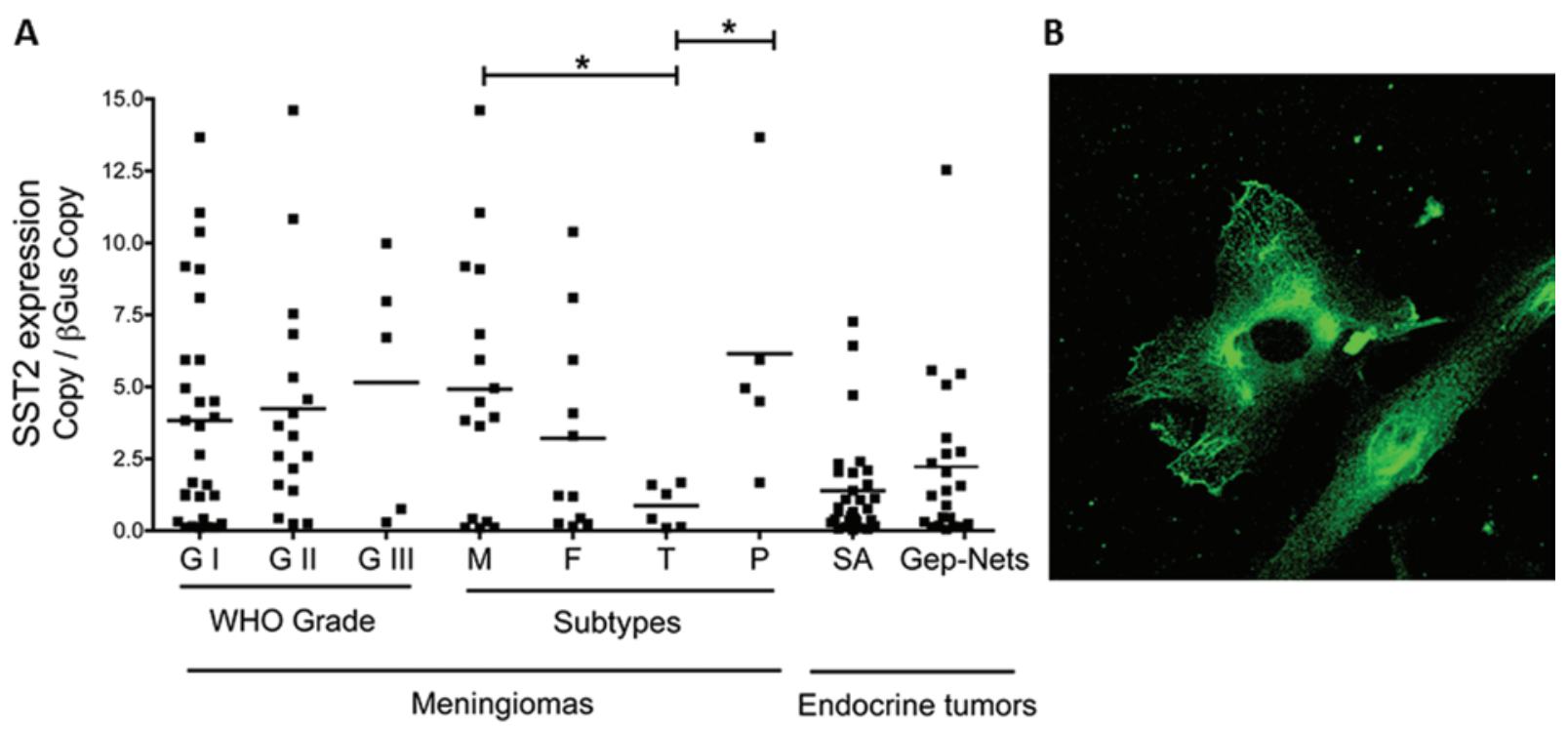

FIG. 1. SST2 expression in meningiomas. A: SST2 mRNA levels were quantified by real-time PCR in a large series of 50 meningiomas, 30 human somatotroph adenomas (SA), and 20 human GEP-NETs. Meningiomas were classified according to WHO grades $(G)$ or histological subtypes: meningothelial $(M)$, fibrous $(F)$, transitional $(T)$, or psammous (P). The level of SST2 mRNA was significantly lower in the transitional subtype than in meningothelial and psammous subtypes ( $\left.{ }^{*} p<0.05\right)$. SST2 mRNA levels, whatever the category of meningioma considered, were similar to those observed in human somatotroph adenomas or GEP-NETs. B: Immunostaining of SST2 in a meningioma cell showed membrane and cytosolic expression. Original magnification $\times 100$. Figure is available in color online only.

\section{Western Blot Analysis}

Twenty-hours after seeding, cells were incubated in low-serum media for 16 hours and then treated with octreotide $\left(10^{-9} \mathrm{M}\right)$ for 3 or 16 hours, depending on the experiment. Meningioma lysates were obtained by mechanical homogenization in lysis buffer. ${ }^{12}$ The denatured proteins $(25 \mu \mathrm{g})$ were separated on $10 \%$ or $15 \%$ SDS-PAGE gels and transferred to polyvinyl difluoride membrane (Perkin Elmer). After blocking, the membrane was incubated with primary antibody overnight at $4{ }^{\circ} \mathrm{C}$, followed by incubation with horseradish peroxidase-conjugated secondary antibody. The proteins were detected using Lumina Forte Western HRP substrate (EMD Millipore Corp.) in a G:BOX (Ozyme Corp.). Primary antibodies were mouse monoclonal antibodies against merlin, SHP1, cyclin D1, S6 ribosomal protein (S6), phospho-S6 ribosomal protein Ser235/Ser236 (p-S6), Akt, phospho-Akt Ser473 (p-Akt), ERK (1/2), phospho-ERK Thr202/Tyr204 (p-ERK), IRS1, phospho-IRS1 Ser636/Ser639 (p-IRS1), and $\beta$-actin. All antibodies were purchased from Cell Signaling Technology Inc.

SHP1-proteins were immunoprecipitated using the Protein G Immunoprecipitation Kit (Sigma-Aldrich). The immunoprecipitated proteins were analyzed by Western blotting.

\section{Detection of SST2 mRNA}

SST2 mRNA expression was assessed using real-time polymerase chain reaction (PCR). Fifty meningiomas were analyzed. Total RNA was extracted from $2.5 \times 10^{5}$ cells and reverse-transcribed into complementary DNA (cDNA) using Superscript II Reverse Transcriptase (ThermoFisher Scientific Inc.). The 5' exonuclease (Taq man) assay was used for quantifying SST2 mRNA, and SST2 mRNA levels were normalized to those of $\beta$-glucuronidase ( $\beta \mathrm{Gus}){ }^{41} \mathrm{~A}$ series of 30 human somatotroph adenomas and 20 GEP-NETs (the usual targets of octreotide) were analyzed in parallel.

\section{Immunocytochemistry}

The expression and localization of SST2 were assessed by immunocytochemistry. Meningioma cells were cultured and then fixed with $4 \%$ paraformaldehyde in phosphate-buffered saline (PBS) for 10 minutes at room temperature. Cells were incubated overnight at $4^{\circ} \mathrm{C}$ with SST2 polyclonal antibody (ss-870, Gramsch Lab Germany) diluted 1:1000 in PBS ( $4^{\circ} \mathrm{C}$ overnight) and detected using Alexa Fluor 488-conjugated anti-goat and anti-rabbit IgG (1:800 in PBS containing 10\% nonimmuno-goat serum; ThermoFisher Scientific Inc.). The cells were treated with Prolong Gold Antifade reagent and visualized on a Zeiss LSH 780 laser scanning microscope equipped with a $100 \times$ oil immersion lens.

\section{Methodology for Meta-Analytic Review}

A PubMed literature search was performed for all English-language publications reporting on the expression of SST2 in meningiomas and the use of octreotide therapy for the treatment of meningiomas. The meta-analysis aimed to study SST2 expression in meningiomas with regard to quantification technique and patient outcomes. The key words "somatostatin" and "meningioma" were used for the SST2 expression search, and "octreotide" and "meningioma" were used for the octreotide therapy search. All identified series and case reports were included in our analysis. 

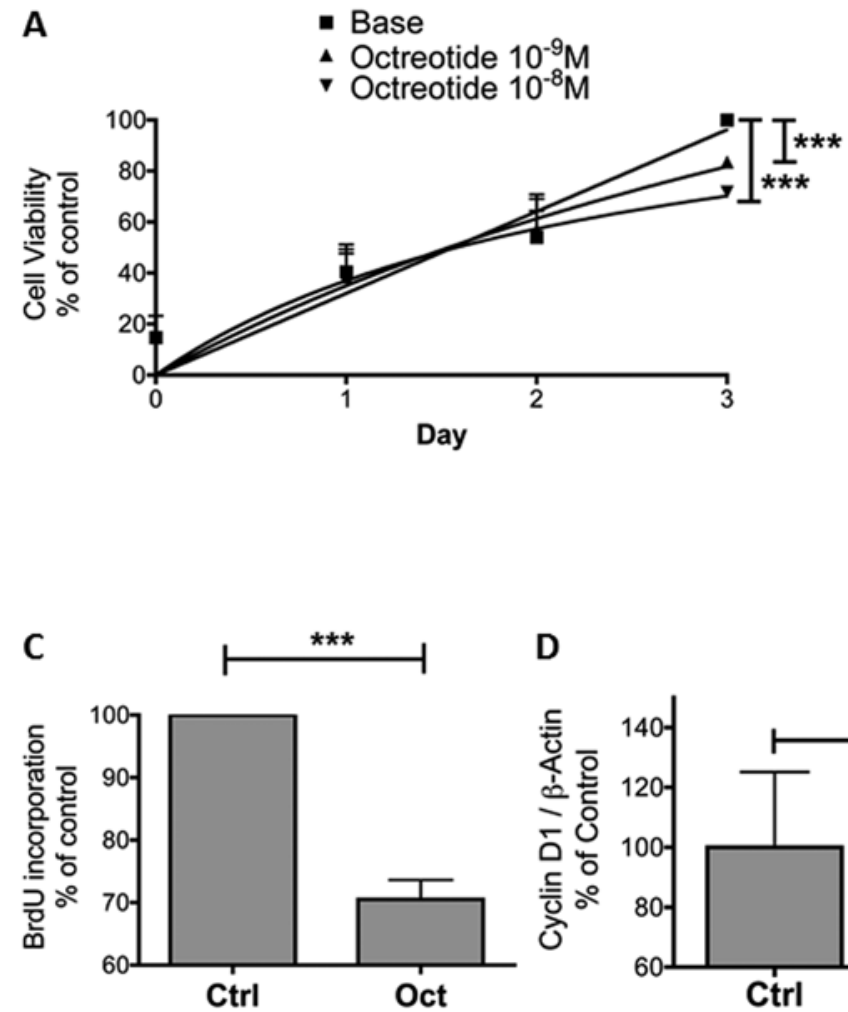

D

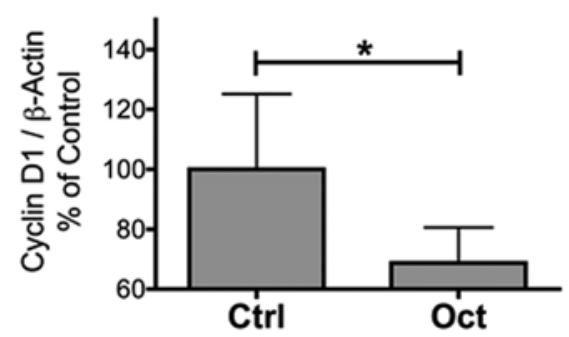

B

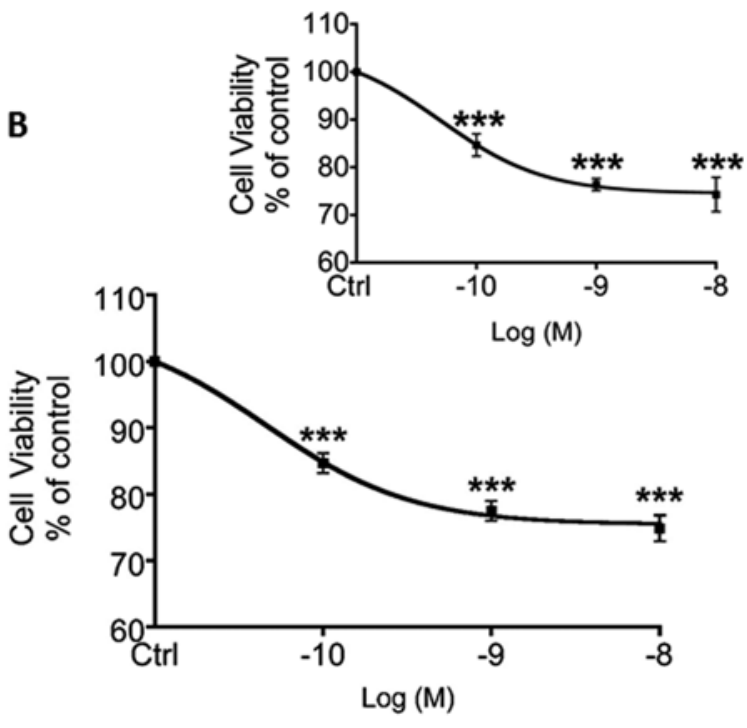

E

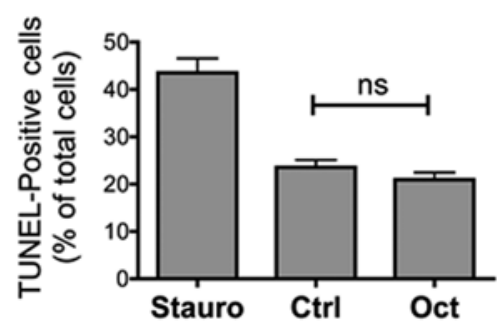

FIG. 2. Octreotide significantly decreased meningioma cell proliferation. A: Mean cell proliferation in 4 meningiomas (3 WHO Grade I meningiomas including 2 fibrous and 1 meningothelial subtypes and 1 WHO Grade II atypical meningioma) cultured under basal conditions (base) or treated with octreotide $\left(10^{-9} \mathrm{M}\right.$ or $10^{-8} \mathrm{M}$ for 3 days). Cell number was evaluated every day. A significant effect of octreotide was observed on the 3rd day of culture (base vs $10^{-9} \mathrm{M}$ or $10^{-8} \mathrm{M}$ of octreotide). B: Dose-effect curve of octreotide treatment (10-10 to $10^{-8} \mathrm{M}$ for 3 days) on cell viability in 34 meningiomas (23 WHO Grade I, 10 WHO Grade II, and 1 WHO Grade III tumors) in primary culture. Inset: Cell viability in 10 WHO Grade II and 1 WHO Grade III tumors. Results are expressed as the mean percent cell viability versus control (untreated cells). C: Effect of octreotide treatment $\left(10^{-9} \mathrm{M}\right.$ for 2 days) on BrdU incorporation in 14 meningiomas (9 WHO Grade I, 4 WHO Grade II, and 1 WHO Grade III tumors). Results are expressed as mean percent of control. D: Immunoblot analysis of cyclin D1 and $\beta$-actin in 10 meningiomas treated with octreotide $\left(10^{-9} \mathrm{M}\right.$, overnight). The results are represented as the mean percentage of cyclin D1/ $\beta$-actin signal versus control. E: TUNEL analysis in 5 meningiomas (2 WHO Grade I and 3 WHO Grade II tumors) treated with octreotide $\left(10^{-9} \mathrm{M}\right)$. The number of apoptotic events was not different between octreotide-treated and untreated cells, whereas an increase was observed under staurosporine treatment $\left(10^{-10} \mathrm{M}\right) .{ }^{*} p<0.05 ;{ }^{* * * *} p>0.0001 ; \mathrm{Ctrl}=$ control; $n s=$ not significant; Oct $=$ octreotide; Stauro = staurosporine.

\section{Statistical Analysis}

Results are presented as the mean \pm standard error of the mean. The statistical significance between 2 unpaired groups was determined using the Mann-Whitney U-test and between 2 paired groups by the Wilcoxon rank-sum test. To measure the strength of association between pairs of variables without specifying dependency, Spearman rank-order correlations were performed. Differences were considered to be significant at $\mathrm{p}<0.05$.

\section{Results}

\section{SST2 Expression in Meningiomas}

SST2 mRNA was expressed in all tumors tested $(>0.01$ SST2 copy//Gus copy; Supplementary Table); SST2 expression was high (> 1 SST2 copy/ $\beta$ Gus copy) in $74.5 \%$ of tumors (Fig. 1A). ${ }^{11}$ No correlation was observed between the SST2 expression level and the WHO grade of the tu- mor. SST2 mRNA expression was significantly lower in the transitional subtype than in the meningothelial and psammous subtypes ( $\mathrm{p}=0.04$ and $\mathrm{p}=0.02$, respectively). SST2 mRNA levels for all categories of meningiomas were similar to those observed in human somatotroph pituitary adenomas or GEP-NETs. SST2 protein expression was assessed by immunocytochemistry in 3 meningioma primary cell cultures. Intense membrane and dot-shaped cytosolic labeling was observed (Fig. 1B).

\section{Decreased Cell Proliferation Due to Octreotide}

Cell proliferation assays were performed on 4 randomly selected tumors ( 3 WHO Grade I 2 fibrous and 1 meningothelial subtypes] and 1 WHO Grade II atypical meningioma) that had been treated for 3 days under 1 of following conditions: no treatment, $10^{-9} \mathrm{M}$ octreotide treatment, or $10^{-8} \mathrm{M}$ octreotide treatment (Fig. 2A). Both 
A

\section{Octreotide $10^{-9} \mathrm{M}$}

p-Akt

Akt

SHP-1

$\beta$-actin

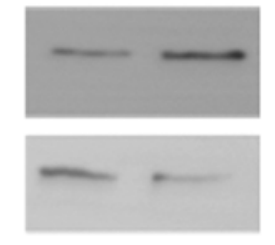

\section{p-ERK}

ERK
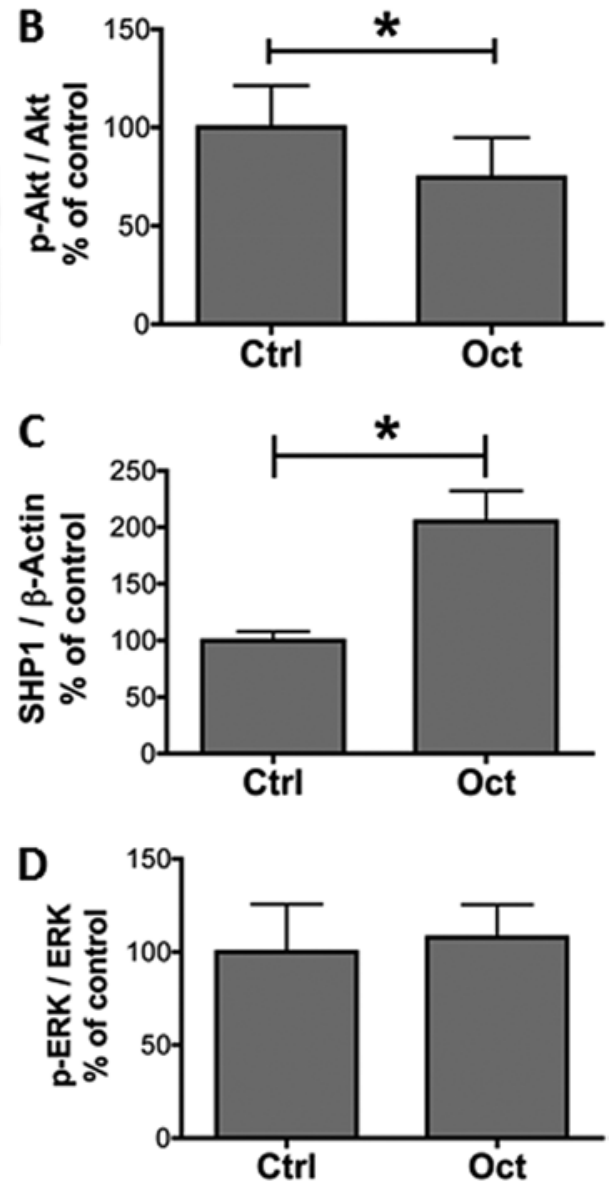

FIG. 3. Octreotide significantly decreased Akt phosphorylation (p-Akt) and increased SHP-1 expression without affecting ERK phosphorylation (p-ERK). A representative immunoblot (A) demonstrating levels of SHP-1, $\beta$-actin, $p$-Akt, total Akt, $p$-ERK, and total ERK1/2 after octreotide treatment (10-9 M, overnight). Quantification of immunoblot signals for SHP-1 versus $\beta$-actin $(n=4$, C), $p$-Akt versus total Akt $(n=14, B)$, and $p$-ERK versus total ERK $(n=10, D)$. The results are represented as the mean percent of control. ${ }^{*} p<0.05$.

concentrations of octreotide reduced cell proliferation in the 4 tested tumors.

The effect of increasing the octreotide dose (ranging from $10^{-10}$ to $10^{-8} \mathrm{M}$, treated for 3 days) was analyzed on 34 meningiomas (Fig. 2B): 23 WHO Grade I tumors, 10 WHO Grade II, and 1 WHO Grade III. Among the WHO Grade I tumors, there were 11 meningothelial, 8 fibrous, 5 psammous, and 3 transitional subtypes (note that some tumors have a double component and are classified as more than one subtype; Supplementary Table). A significant dose-dependent inhibition in cell viability was observed in $88 \%$ of tested tumors (Fig. 2B). Only 12\% (4/34) were considered to be octreotide "nonresponders" (inhibition < 10\%). Octreotide decreased cell viability by $26 \%$, but the decrease in cell viability was not significantly different between WHO Grade I and WHO Grade II or III tumors (Fig. 2B: all WHO grades; Fig. 2B inset: WHO Grades II and III). The mean reduction in cell viability was $27 \%$ in meningothelial subtypes, $23 \%$ in fibrous, $29 \%$ in transitional, and $13 \%$ in psammous, and the latter was significantly lower than the other subtypes ( $p<0.05$, Supplementary Fig. 1). There was no significant difference in viability between the $10^{-8} \mathrm{M}$ and $10^{-9} \mathrm{M}$ doses of octreotide (26.5\% and $27.5 \%$, respectively).
Since a dose of $10^{-9} \mathrm{M}$ corresponds to the octreotide plasma concentration in patients treated for acromegaly, ${ }^{49}$ this concentration was used for the subsequent experiments.

The cell viability results were confirmed by direct cell counting on 3 meningiomas (data not shown) and by BrdU incorporation (Fig. 2C). Octreotide treatment $\left(10^{-9} \mathrm{M}\right.$ for 3 days) decreased BrdU incorporation in 13 of the 14 meningiomas tested (inhibition $>10 \%$ ), which included 9 WHO Grade I, 4 WHO Grade II, and 1 WHO Grade III tumors. The mean decrease in cell proliferation was $31 \%$. Moreover, octreotide decreased cyclin D1 expression (Fig. 2D and Supplementary Fig. 2).

In slow-growing tumors such as somatotroph adenomas, octreotide induced cell death by a caspase-dependent mechanism. ${ }^{1}$ To understand the impact of octreotide on cell viability, the apoptotic pathway was considered. The number of apoptotic events, determined by TUNEL assay in 5 tumors (2 WHO Grade I and 3 WHO Grade II), was not different between octreotide-treated $\left(10^{-9} \mathrm{M}\right)$ and untreated cells, while a clear increase in TUNEL-positive cells was observed after treatment with the apoptosis inducer staurosporine (Fig. 2E). Moreover, octreotide treatment $\left(10^{-9} \mathrm{M}\right)$ did not increase caspase activity in the 6 

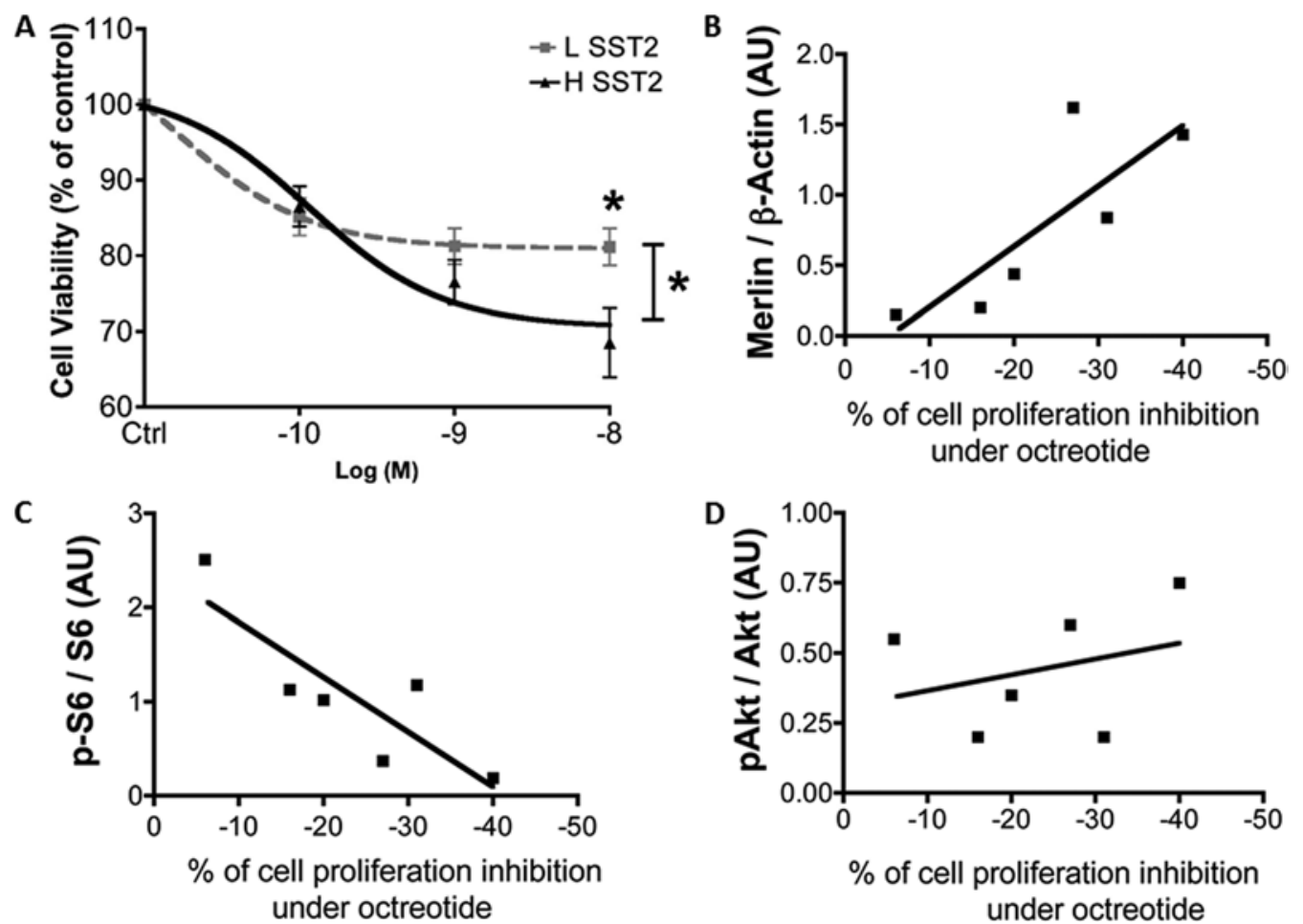

FIG. 4. Comparison of octreotide-induced inhibition of cell proliferation with SST2 mRNA expression, merlin protein expression, or S6 phosphorylation ( $p$-S6). Dose-effect curve (A) of octreotide treatment on cell viability in the high-SST2 group and the low-SST2 group. Cell viability was significantly lower in the high-SST2 group than in the low-SST2 group. Correlation between cell proliferation and total merlin expression (B), S6 phosphorylation (C), or Akt phosphorylation (D) in 6 meningiomas treated with octreotide (3 WHO Grade I, 2 WHO Grade II, and 1 WHO Grade III). Merlin expression, S6 phosphorylation, and Akt phosphorylation were quantified by Western blot. Octreotide sensitivity was evaluated by calculating the percent inhibition of cell proliferation as assessed by BrdU incorporation with octreotide treatment $\left(10^{-9} \mathrm{M}\right) . r=-0.8, p=0.04$ (B). $r=0.8, p=0.03(\mathrm{C})$. ${ }^{*} p<0.05 ;$ H SST2 = high-SST2 group; L SST2 = low-SST2 group.

meningiomas tested (3 WHO Grade I and 3 WHO Grade II; Supplementary Fig. 3).

\section{Transduction Pathways Involved in Octreotide Effects on Meningiomas}

To decipher the signal transduction pathways involved in octreotide-induced inhibition of cell proliferation, Akt, SHP-1, and ERK were analyzed by Western blotting. Octreotide treatment $\left(10^{-9} \mathrm{M}\right)$ significantly decreased Akt phosphorylation in 14 tested meningiomas (10 WHO Grade I and 4 WHO Grade II tumors; Fig. 3A and B) and increased total SHP-1 expression in 4 tested meningiomas (2 WHO Grade I and 2 WHO Grade II tumors; Fig. 3A and C). However, no effect was observed on ERK phosphorylation (Fig. 3A and D).

\section{Octreotide Antiproliferative Effect}

Even though psammous meningiomas, which exhibited the lowest octreotide response, and transitional meningiomas, which expressed the lowest SST2 level, were excluded, we did not observe any correlation between levels of SST2 mRNA and inhibition of cell viability by octreotide. However, when meningiomas were classified into 2 groups according to SST2 mRNA expression (low-SST2 group: < 2 SST2 copies/ $\beta$ Gus copy $[\mathrm{n}=16]$ and high-SST2 group: $\geq 2$ SST2 copies/ $\beta$ Gus copy $[n=9]$ ), octreotide had a significantly higher inhibitory effect on cell viability in the high-SST2 group than in the low-SST2 group (Fig. 4A).

To identify other molecular markers of octreotide sensitivity, we analyzed 6 meningiomas (3 WHO Grade I, 2 WHO Grade II, and 1 WHO Grade III) for expression and phosphorylation status of 3 intracellular proteins crucial in meningiomas tumorigenesis: ${ }^{20}$ total merlin, phosphoAkt, and phospho-S6. Merlin is encoded by the NF2 gene and is mutated in a majority of meningiomas, resulting in a loss of protein expression. Merlin is a negative regulator of mTORC1, a downstream regulator of the PI3k/Akt/ mammalian target of rapamycin (mTOR) pathway. ${ }^{22} \mathrm{We}$ then compared these molecular markers to the percent of cell proliferation inhibition after treatment with octreotide $\left(10^{-9} \mathrm{M}\right)$. Inhibition of cell proliferation was strongly positively correlated with merlin expression $(p=0.04, r=$ -0.8 ; Fig. 4B) and inversely correlated with levels of S6 phosphorylation ( $\mathrm{p}=0.03, \mathrm{r}=0.8)$, a marker of mTORC1 activity (Fig. 4C). However, we did not observe any correlation between inhibition of cell proliferation and Akt phosphorylation (Fig. 4D).

\section{Discussion}

The antitumoral effects of somatostatin analogs on 
TABLE 1. Literature survey of SST2 expression in meningiomas: 1998-2016

\begin{tabular}{lccccccccc}
\hline \multicolumn{1}{c}{ Study } & $\begin{array}{c}\text { Present } \\
\text { Study }\end{array}$ & $\begin{array}{c}\text { Silva et } \\
\text { al., 2015 }\end{array}$ & $\begin{array}{c}\text { Agaimy et } \\
\text { al., 2014 }\end{array}$ & $\begin{array}{c}\text { Barresi et } \\
\text { al., 2008 }\end{array}$ & $\begin{array}{c}\text { Durand et } \\
\text { al., 2008 }\end{array}$ & $\begin{array}{c}\text { Arena et } \\
\text { al., 2004 }\end{array}$ & $\begin{array}{c}\text { Schulz et } \\
\text { al., 2000 }\end{array}$ & $\begin{array}{c}\text { Dutour et } \\
\text { al., } 1998\end{array}$ \\
\hline No. of tumors & 50 & 60 & 68 & 35 & 22 & 26 & 42 & 40 & 20 \\
\hline Method & PCR & IHC & IHC & IHC & IHC & PCR & PCR & IHC & PCR \\
\hline SST2 subtype A expression (\%)* & 100 & 100 & 87 & 74 & 64 & 100 & 79 & 70 & 100 \\
\hline IHC = immunohistochemistry. \\
${ }^{*}$ Results are expressed as the percentage of SST2-expressing tumors.
\end{tabular}

meningiomas in vivo has been previously suggested ${ }^{27}$ but poorly documented. In fact, conducting informative clinical studies is challenging for this type of slow-growing tumor. Therefore, the relevance of many clinical studies remains limited. Somatostatin analogs are well tolerated even at high doses, highlighting the interest in this long-term treatment for slow-growing tumors such as GEP-NETs, somatotroph adenomas, and potentially meningiomas. In agreement with US Food and Drug Administration considerations, octreotide is currently one of the rare drugs recommended for the treatment of patients with meningiomas.

SST2 mRNA was detected in all 50 of the randomly selected meningiomas in our series. The level of SST2 mRNA was high in $74.5 \%$ of tested meningiomas, but there was no correlation between SST2 mRNA levels and WHO tumor grades. Our results were in agreement with immunohistochemical data from other groups, showing high SST2 expression in 69\% of tumors (Table 1)..$^{2,4,5,14,15,43,44}$ For the first time, we demonstrated that the range of SST2 mRNA levels in meningiomas was similar to that observed in somatotroph tumors or GEP-NETs, the 2 main tumor families targeted by somatostatin analogs in clinical practice.

Although the antitumoral effect of octreotide has been described in isolated cases of meningiomas, ${ }^{18,21,38,40}$ only 4 clinical studies have aimed to assess this question (Table
2). ${ }^{10,23,42,45}$ Three trials were performed on patients with aggressive and recurrent meningiomas, while 1 trial was conducted on patients with WHO Grade I skull base meningiomas who had not received prior radiotherapy or chemotherapy ${ }^{42}$ For all but 1 of these studies, ${ }^{42}$ the main limitation was their short duration. Octreotide was well tolerated in all cases, regardless of the dose or the galenic form used.

According to our review of the literature (Table 2), the distribution of octreotide-treated patients into 3 groups based on outcome-stable disease, partial response, and progressive disease-revealed a statistical difference between the patients with WHO Grade I and those with WHO Grade III meningiomas (chi-square test, $p=0.01$ ), with the best treatment efficacy in WHO Grade I tumors. Recently, Norden et al. conducted a study on the use of the somatostatin analog pasireotide, which binds to SST1, $-2,-3$, and -5 (with the highest affinity for SST5), in 18 recurrent or progressive meningiomas and reported no increase in the proportion of patients experiencing 6-month progression-free survival (PFS6). ${ }^{35}$ The antitumoral effect of somatostatin analogs has clearly been established for patients with GEP-NETs, ${ }^{8,39}$ while the distribution of somatostatin analog-treated patients was not statistically different from that observed for WHO Grade I meningiomas: $45 \%$ in the stable disease group, $2 \%$ in the partial remission group, and $41 \%$ in the progressive disease group. ${ }^{3}$

TABLE 2. Literature review of clinical studies and case reports using octreotide for meningiomas

\begin{tabular}{|c|c|c|c|c|c|c|c|c|c|c|c|c|c|c|c|c|}
\hline \multirow[b]{2}{*}{ Authors \& Year } & \multirow{2}{*}{$\begin{array}{l}\text { No. of } \\
\text { Pts }\end{array}$} & \multirow[b]{2}{*}{ Octeotide Dose } & \multirow{2}{*}{$\begin{array}{l}\text { Oct } \\
\text { Scan }\end{array}$} & \multirow[b]{2}{*}{$\mathrm{IHC}$} & \multicolumn{4}{|c|}{ WHO Grade } & \multirow[b]{2}{*}{ Op } & \multirow[b]{2}{*}{$\mathrm{RT}$} & \multirow[b]{2}{*}{ CT } & \multirow[b]{2}{*}{ PFS6 } & \multirow{2}{*}{$\begin{array}{c}\text { Median } \\
\text { TTP (mos) }\end{array}$} & \multicolumn{3}{|c|}{ BRR } \\
\hline & & & & & ND & 1 & $\|$ & III & & & & & & SD & PR & PD \\
\hline \multicolumn{17}{|l|}{ Clinical studies } \\
\hline Simó et al., 2014 & 9 & 30-40 mg LAR & + & - & 0 & 0 & 5 & 4 & $9 / 9$ & $9 / 9$ & $0 / 9$ & $44 \%$ & 4.2 & 3 & 0 & 6 \\
\hline Johnson et al., 2011 & 11 & $500 \mu \mathrm{g}$ 3/day & - & $6+/ 6$ & 0 & 3 & 3 & 5 & $11 / 11$ & $9 / 11$ & 3 & $30 \%$ & 4.2 & 8 & 0 & 3 \\
\hline Schulz et al., 2011 & 8 & 30 mg LAR & + & - & 0 & 8 & 0 & 0 & $8 / 8$ & $0 / 8$ & $0 / 8$ & $100 \%$ & $>60$ & 8 & 0 & 0 \\
\hline $\begin{array}{l}\text { Chamberlain et al., } \\
2007\end{array}$ & 16 & $30 \mathrm{mg}$ LAR & + & - & 2 & 6 & 3 & 5 & $14 / 16$ & $13 / 16$ & $12 / 16$ & $44 \%$ & 5 & 5 & 5 & 6 \\
\hline \multicolumn{17}{|l|}{ Case reports } \\
\hline Rammo et al., 2016 & 1 & $30 \mathrm{mg}$ LAR & + & + & 0 & 0 & 0 & 1 & $1 / 1$ & $1 / 1$ & $1 / 1$ & & & & & \\
\hline $\begin{array}{l}\text { Jaffrain-Rea et al., } \\
1998\end{array}$ & 1 & $100 \mu \mathrm{g} 3 /$ day & - & - & 1 & 0 & 0 & 0 & 1 & 0 & 0 & & & & & \\
\hline $\begin{array}{l}\text { García-Luna et al., } \\
1993\end{array}$ & 3 & $900-1500 \mu \mathrm{g} / \mathrm{day}$ & - & $1+/ 1$ & 0 & 2 & 0 & 1 & $3 / 3$ & $0 / 3$ & $0 / 3$ & & & & & \\
\hline Rünzi et al., 1989 & 1 & $500 \mu \mathrm{g} 3 /$ day & - & - & 0 & 1 & 0 & 0 & 1 & 0 & 0 & & & & & \\
\hline
\end{tabular}

BRR = best radiological response; $C T$ = chemotherapy; $L A R=$ long-acting repeatable; ND = not determined; Oct Scan = octreotide SPECT scanning; PD = progressive disease; $\mathrm{PR}=$ partial response; $\mathrm{Pts}=$ patients; $\mathrm{RT}$ = radiotherapy; $\mathrm{SD}=$ stable disease; $\mathrm{TTP}$ = time to progression. 
TABLE 3. Literature review: assessment of PFS6 and BRR in clinical studies of octreotide for meningioma, by WHO grade*

\begin{tabular}{lccccc}
\hline & No. of & PFS6 & \multicolumn{3}{c}{ BRR (no. [\%]) } \\
\cline { 5 - 7 } Tumor Grade & Pts & (no. [\%]) & SD & PR & PD \\
\hline WHO Grade I & 19 & $13(68.4)$ & $13(68.4)$ & $3(15.8)$ & $3(15.8)$ \\
\hline $\begin{array}{c}\text { Skull Base } \\
\text { WHO Grade I }\end{array}$ & 13 & $12(92.3)$ & $9(69.2)$ & $3(23.1)$ & $1(7.7)$ \\
\hline WHO Grade II & 11 & $4(36.5)$ & $6(54.6)$ & $1(9)$ & $4(36.4)$ \\
\hline WHO Grade III & 14 & $4(28.5)$ & $4(28.6)$ & $1(7.1)$ & $9(64.3)$ \\
\hline
\end{tabular}

* Chamberlain et al., 2007; Johnson et al., 2011; Schulz et al., 2011; Simó et al., 2014.

According to the benchmarks of the Response Assessment in Neuro-Oncology (RANO) criteria, ${ }^{24}$ the effects of octreotide should be considered significant in patients with WHO Grade I meningiomas when the PFS6 level averages more than 50\%. A PFS6 level approaching 92\% was observed in WHO Grade I skull base meningiomas (Table 3). ${ }^{10,42}$ Overall, these data clearly demonstrate the efficacy of somatostatin analogs for WHO Grade I meningiomas. Although octreotide had a clear inhibitory effect on cell viability in vitro for WHO Grade II or III meningiomas, it did not appear to be an efficient treatment (based on PFS6 assessment) in vivo. ${ }^{10,23,45}$ However, the PFS6 criterion does not take tumor growth rate into consideration; therefore, a putative decrease in growth rate is not assessed.

Our in vitro data clearly support the results of in vivo studies using octreotide therapy for meningiomas. Although SST2 expression was well characterized in meningiomas, $5,15,43$ the cellular and molecular mechanisms triggered by somatostatin analogs remains somewhat unknown. This is essentially attributable to the difficulty in performing primary cultures for this type of tumor compared with other CNS tumors such as glioma. ${ }^{4,26}$ In our large series of human meningiomas, octreotide clearly inhibits cell proliferation in vitro. This effect was significant $(>10 \%)$ in $88 \%$ of the tested tumors regardless of their WHO grade. Our results were in agreement with those of Arena et al., who showed a decrease in cell proliferation by thymidine incorporation in a smaller series (4/7) of meningiomas. ${ }^{4}$ In contrast, Koper et al. reported an increase in cell proliferation with octreotide treatment using the same protocol. ${ }^{26}$ However, experiments from the Koper study were not performed days after surgical removal, as was done in our study, but several weeks after instead. During this time lapse, many native molecular features, such as receptor membrane expression, are likely to be lost. ${ }^{6,20}$

Somatostatin analogs may exert their antiproliferative action directly by blocking cell division or by inducing apoptosis. In contrast to the situation for other slow-growing tumors, such as GEP-NETs ${ }^{33}$ or somatotroph tumors, ${ }^{1}$ the inhibition of cell viability by octreotide in meningiomas in vitro was not the result of apoptosis. Therefore, considering the direct effect of somatostatin analogs, we expected the clinical effect of octreotide to control tumor growth rather than induce tumor shrinkage.

It has been reported that SST2 mediates cell growth arrest by regulating several signal transduction pathways, including the ERK and PI3K/Akt pathways, and by activating tyrosine phosphatases. ${ }^{37}$ In contrast to pituitary adenomas, octreotide did not modulate ERK phosphorylation levels in meningiomas; however, Akt phosphorylation was clearly inhibited. In addition, the inhibition of cell proliferation by octreotide was inversely correlated with the activation (phosphorylation) of S6 kinase, a downstream effector of mTOR. Consequently, mTOR hyperactivation may limit the antiproliferative effect of octreotide. We show that expression levels of merlin protein are strongly positively correlated to octreotide response; therefore, it may be a relevant marker for in vivo octreotide sensitivity. ${ }^{22,32}$ The significant increase in the levels of SHP1 protein observed in our study suggests that upregulation of SHP1 could be an important step for SST2-mediated antiproliferative signaling in meningioma, as was previously demonstrated in pancreatic adenocarcinoma ${ }^{31}$ and tumoral pituitary cells. ${ }^{46}$

In addition to their direct antitumoral effect, somatostatin analogs also exert crucial peritumoral action in vivo, either antiangiogenic or antiinflammatory. SSTs are expressed in growing vascular endothelial cells. ${ }^{48}$ An antiangiogenic effect of octreotide, inhibiting VEGF signaling, has been demonstrated in neuroendocrine tumors and pituitary adenomas. ${ }^{28,47}$ Some meningiomas lead to peritumoral brain edema, ${ }^{13,19,25,34}$ causing increased morbidity. Peritumoral brain edema is correlated to VEGF mRNA expression levels and to meningioma vascularization. ${ }^{29,34}$ Improvements in neurological symptoms (visual improvement and headache alleviation) have been reported under octreotide treatment without a tumor volume change. ${ }^{18,21}$ These clinical observations emphasize the relevance of somatostatin analogs through indirect meningioma antitumoral effects.

In our study, we observed a better octreotide response on cell viability in those meningiomas expressing high levels of SST2. Nevertheless, there was no significant correlation between octreotide response and SST2 mRNA levels. For instance, in meningiomas with a transitional subtype, a significantly low level of SST2 expression was observed (lower than in psammous meningiomas), which was associated with a paradoxical significantly better octreotide effect. In agreement with our data, no correlation was observed between radiolabeled octreotide uptake during SPECT scanning and clinical octreotide antitumoral effect. ${ }^{10,23}$ Overall, according to our data and those from the literature, the assessment of SST2 expression level seems to be an inaccurate marker in predicting octreotide response.

Clinical studies have highlighted an antitumoral effect of octreotide in WHO Grade I meningiomas and particularly in skull base meningiomas. ${ }^{10,42}$ This could be explained by 2 molecular characteristics of these tumors, which are found in the majority of tumors from the meningothelial subtype: a high SST2 expression level combined with a low rate of $N F 2$ gene mutation, resulting in merlin protein expression. ${ }^{14,50}$ Therefore, somatostatin analog treatment should be advised for extended skull base meningiomas such as petroclival meningiomas or for those that produce undesirable symptoms, are located in areas that are difficult to access via surgery, or display tumor extension incompatible with radiotherapy. Somatostatin analogs could also be an interesting and relevant alternative 
for asymptomatic, slow-growing meningiomas in elderly patients or those with a degraded general status, who may have uncertain outcomes under general anesthesia and/ or unreasonable surgery. Moreover, somatostatin analogs are well-tolerated drugs, allowing long-term treatment for several years, as in acromegaly or neuroendocrine tumors.

\section{Conclusions}

We demonstrated the antiproliferative activity of the somatostatin agonist octreotide in meningiomas in vitro. Clinical studies suggest an interest in octreotide for the treatment of patients with slow-growing meningiomas, particularly skull base WHO Grade I tumors. In aggressive meningiomas, the clinical effects of octreotide seem clinically insufficient. Finally, somatostatin analogs could be of interest in therapeutic strategies that combine somatostatin analogs with mTOR inhibitors, targeting one of the crucial signaling pathways involved in meningioma tumorigenesis. ${ }^{20}$

\section{Acknowledgments}

We thank Christophe Lisbonis for his help in primary cell culture of meningioma. We also thank Anne-Laure Germanetti from APHM Molecular Biology Laboratory for the SST2 mRNA quantification. Tumor specimens were stored in the AP-HM tumor bank AC 2013-1786. We thank ENAGO (www.enago.com) for the English-language review.

This work was supported by Centre National de la Recherche Scientifique (CNRS UMR 7286), Aix-Marseille University.

\section{References}

1. Acunzo J, Thirion S, Roche C, Saveanu A, Gunz G, Germanetti AL, et al: Somatostatin receptor sst 2 decreases cell viability and hormonal hypersecretion and reverses octreotide resistance of human pituitary adenomas. Cancer Res 68:10163-10170, 2008

2. Agaimy A, Buslei R, Coras R, Rubin BP, Mentzel T: Comparative study of soft tissue perineurioma and meningioma using a five-marker immunohistochemical panel. Histopathology 65:60-70, 2014

3. Appetecchia M, Baldelli R: Somatostatin analogues in the treatment of gastroenteropancreatic neuroendocrine tumours, current aspects and new perspectives. J Exp Clin Cancer Res 29:19, 2010

4. Arena S, Barbieri F, Thellung S, Pirani P, Corsaro A, Villa V, et al: Expression of somatostatin receptor mRNA in human meningiomas and their implication in in vitro antiproliferative activity. J Neurooncol 66:155-166, 2004

5. Barresi V, Alafaci C, Salpietro F, Tuccari G: Sstr2A immunohistochemical expression in human meningiomas: is there a correlation with the histological grade, proliferation or microvessel density? Oncol Rep 20:485-492, 2008

6. Blankenstein MA, Verheijen FM, Jacobs JM, Donker TH, van Duijnhoven MW, Thijssen JH: Occurrence, regulation, and significance of progesterone receptors in human meningioma. Steroids 65:795-800, 2000

7. Bousquet C, Guillermet-Guibert J, Saint-Laurent N, ArcherLahlou E, Lopez F, Fanjul M, et al: Direct binding of p85 to sst2 somatostatin receptor reveals a novel mechanism for inhibiting PI3K pathway. EMBO J 25:3943-3954, 2006

8. Caplin M, Pavel M, Cwikla JB, Phan A, Raderer M, Sedlackova E, et al: Antitumor effects of lanreotide for pancreatic and intestinal neuroendocrine tumors. Endocr Relat Cancer, 2016
9. Chamberlain MC: The role of chemotherapy and targeted therapy in the treatment of intracranial meningioma. Curr Opin Oncol 24:666-671, 2012

10. Chamberlain MC, Glantz MJ, Fadul CE: Recurrent meningioma: salvage therapy with long-acting somatostatin analogue. Neurology 69:969-973, 2007

11. de Bruin C, Pereira AM, Feelders RA, Romijn JA, Roelfsema F, Sprij-Mooij DM, et al: Coexpression of dopamine and somatostatin receptor subtypes in corticotroph adenomas. J Clin Endocrinol Metab 94:1118-1124, 2009

12. Defilles C, Lissitzky JC, Montero MP, André F, Prévot C, Delamarre E, et al: $\alpha v \beta 5 / \beta 6$ integrin suppression leads to a stimulation of $\alpha 2 \beta 1$ dependent cell migration resistant to PI3K/Akt inhibition. Exp Cell Res 315:1840-1849, 2009

13. Ding YS, Wang HD, Tang K, Hu ZG, Jin W, Yan W: Expression of vascular endothelial growth factor in human meningiomas and peritumoral brain areas. Ann Clin Lab Sci 38:344-351, 2008

14. Durand A, Champier J, Jouvet A, Labrousse F, Honnorat J, Guyotat J, et al: Expression of c-Myc, neurofibromatosis Type 2, somatostatin receptor 2 and erb-B2 in human meningiomas: relation to grades or histotypes. Clin Neuropathol 27:334-345, 2008

15. Dutour A, Kumar U, Panetta R, Ouafik L, Fina F, Sasi R, et al: Expression of somatostatin receptor subtypes in human brain tumors. Int J Cancer 76:620-627, 1998

16. Ferjoux G, Lopez F, Esteve JP, Ferrand A, Vivier E, Vely F, et al: Critical role of Src and SHP-2 in sst2 somatostatin receptor-mediated activation of SHP-1 and inhibition of cell proliferation. Mol Biol Cell 14:3911-3928, 2003

17. Furtner J, Schopf V, Seystahl K, Le Rhun E, Ruda R, Roelcke $\mathrm{U}$, et al: Kinetics of tumor size and peritumoral brain edema before, during, and after systemic therapy in recurrent WHO grade II or III meningioma. Neuro Oncol 18:401-407, 2015

18. García-Luna PP, Relimpio F, Pumar A, Pereira JL, Leal-Cerro A, Trujillo F, et al: Clinical use of octreotide in unresectable meningiomas. A report of three cases. J Neurosurg Sci 37:237-241, 1993

19. Goldman CK, Bharara S, Palmer CA, Vitek J, Tsai JC, Weiss $\mathrm{HL}$, et al: Brain edema in meningiomas is associated with increased vascular endothelial growth factor expression. Neurosurgery 40:1269-1277, 1997

20. Graillon T, Defilles C, Mohamed A, Lisbonis C, Germanetti AL, Chinot O, et al: Combined treatment by octreotide and everolimus: Octreotide enhances inhibitory effect of everolimus in aggressive meningiomas. J Neurooncol 124:33-43, 2015

21. Jaffrain-Rea ML, Minniti G, Santoro A, Bastianello S, Tamburrano G, Gulino A, et al: Visual improvement during octreotide therapy in a case of episellar meningioma. Clin Neurol Neurosurg 100:40-43, 1998

22. James MF, Han S, Polizzano C, Plotkin SR, Manning BD, Stemmer-Rachamimov AO, et al: NF2/merlin is a novel negative regulator of mTOR complex 1 , and activation of mTORC1 is associated with meningioma and schwannoma growth. Mol Cell Biol 29:4250-4261, 2009

23. Johnson DR, Kimmel DW, Burch PA, Cascino TL, Giannini $\mathrm{C}, \mathrm{Wu} \mathrm{W}$, et al: Phase II study of subcutaneous octreotide in adults with recurrent or progressive meningioma and meningeal hemangiopericytoma. Neuro Oncol 13:530-535, 2011

24. Kaley T, Barani I, Chamberlain M, McDermott M, Panageas $\mathrm{K}$, Raizer J, et al: Historical benchmarks for medical therapy trials in surgery- and radiation-refractory meningioma: a RANO review. Neuro Oncol 16:829-840, 2014

25. Kalkanis SN, Carroll RS, Zhang J, Zamani AA, Black PM: Correlation of vascular endothelial growth factor messenger RNA expression with peritumoral vasogenic cerebral edema in meningiomas. J Neurosurg 85:1095-1101, 1996

26. Koper JW, Markstein R, Kohler C, Kwekkeboom DJ, Avezaat 
CJ, Lamberts SW, et al: Somatostatin inhibits the activity of adenylate cyclase in cultured human meningioma cells and stimulates their growth. J Clin Endocrinol Metab 74:543547, 1992

27. Kunert-Radek J, Stepien H, Radek A, Pawlikowski M: Somatostatin suppression of meningioma cell proliferation in vitro. Acta Neurol Scand 75:434-436, 1987

28. Kurosaki M, Saegert W, Abe T, Lüdecke DK: Expression of vascular endothelial growth factor in grow th hormone-secreting pituitary adenomas: special reference to the octreotide treatment. Neurol Res 30:518-522, 2008

29. Lamszus K, Lengler U, Schmidt NO, Stavrou D, Ergün S, Westphal M: Vascular endothelial growth factor, hepatocyte growth factor/scatter factor, basic fibroblast growth factor, and placenta growth factor in human meningiomas and their relation to angiogenesis and malignancy. Neurosurgery 46:938-948, 2000

30. Le Duc-Pennec A, Thol C, Cavarec M, Le Rest C, Turzo A, Guillo P, et al: Octreotide imaging plus bone scintigrams to optimally localize gastroenteropancreatic neuroendocrine tumors. Clin Nucl Med 28:5-8, 2003

31. Lopez F, Estève JP, Buscail L, Delesque N, Saint-Laurent N, Théveniau M, et al: The tyrosine phosphatase SHP-1 associates with the sst 2 somatostatin receptor and is an essential component of sst2-mediated inhibitory growth signaling. J Biol Chem 272:24448-24454, 1997

32. López-Lago MA, Okada T, Murillo MM, Socci N, Giancotti FG: Loss of the tumor suppressor gene NF2, encoding merlin, constitutively activates integrin-dependent mTORC signaling. Mol Cell Biol 29:4235-4249, 2009

33. Mohamed A, Blanchard MP, Albertelli M, Barbieri F, Brue T, Niccoli P, et al: Pasireotide and octreotide antiproliferative effects and $\mathrm{sst}_{2}$ trafficking in human pancreatic neuroendocrine tumor cultures. Endocr Relat Cancer 21:691-704, 2014

34. Nassehi D, Dyrbye H, Andresen M, Thomsen C, Juhler M, Laursen H, et al: Vascular endothelial growth factor A protein level and gene expression in intracranial meningiomas with brain edema. APMIS 119:831-843, 2011

35. Norden AD, Ligon KL, Hammond SN, Muzikansky A, Reardon DA, Kaley TJ, et al: Phase II study of monthly pasireotide LAR (SOM230C) for recurrent or progressive meningioma. Neurology 84:280-286, 2015

36. Putman M, Burton R, Nahm MH: Simplified method to automatically count bacterial colony forming unit. J Immunol Methods 302:99-102, 2005

37. Pyronnet S, Bousquet C, Najib S, Azar R, Laklai H, Susini C: Antitumor effects of somatostatin. Mol Cell Endocrinol 286:230-237, 2008

38. Rammo R, Rock A, Transou A, Raghunathan A, Rock J: Anaplastic meningioma: octreotide therapy for a case of recurrent and progressive intracranial disease. J Neurosurg 124:496-500, 2016

39. Rinke A, Müller HH, Schade-Brittinger C, Klose KJ, Barth $\mathrm{P}$, Wied M, et al: Placebo-controlled, double-blind, prospective, randomized study on the effect of octreotide LAR in the control of tumor growth in patients with metastatic neuroendocrine midgut tumors: a report from the PROMID Study Group. J Clin Oncol 27:4656-4663, 2009

40. Rünzi MW, Jaspers C, Windeck R, Benker G, Mehdorn HM, Reinhardt V, et al: Successful treatment of meningioma with octreotide. Lancet 1:1074, 1989

41. Saveanu A, Lavaque E, Gunz G, Barlier A, Kim S, Taylor JE, et al: Demonstration of enhanced potency of a chimeric somatostatin-dopamine molecule, BIM-23A387, in suppressing growth hormone and prolactin secretion from human pituitary somatotroph adenoma cells. J Clin Endocrinol Metab 87:5545-5552, 2002

42. Schulz C, Mathieu R, Kunz U, Mauer UM: Treatment of unresectable skull base meningiomas with somatostatin analogs. Neurosurg Focus 30(5):E11, 2011

43. Schulz S, Pauli SU, Schulz S, Händel M, Dietzmann K, Firsching R, et al: Immunohistochemical determination of five somatostatin receptors in meningioma reveals frequent overexpression of somatostatin receptor subtype sst2A. Clin Cancer Res 6:1865-1874, 2000

44. Silva CB, Ongaratti BR, Trott G, Haag T, Ferreira NP, Leães $\mathrm{CG}$, et al: Expression of somatostatin receptors (SSTR1SSTR5) in meningiomas and its clinicopathological significance. Int J Clin Exp Pathol 8:13185-13192, 2015

45. Simó M, Argyriou AA, Macià M, Plans G, Majós C, Vidal N, et al: Recurrent high-grade meningioma: a phase II trial with somatostatin analogue therapy. Cancer Chemother Pharmacol 73:919-923, 2014

46. Theodoropoulou M, Zhang J, Laupheimer S, Paez-Pereda M, Erneux C, Florio T, et al: Octreotide, a somatostatin analogue, mediates its antiproliferative action in pituitary tumor cells by altering phosphatidylinositol 3-kinase signaling and inducing Zac1 expression. Cancer Res 66:1576-1582, 2006

47. Villaume K, Blanc M, Gouysse G, Walter T, Couderc C, Nejjari M, et al: VEGF secretion by neuroendocrine tumor cells is inhibited by octreotide and by inhibitors of the PI3K/AKT/ mTOR pathway. Neuroendocrinology 91:268-278, 2010

48. Watson JC, Balster DA, Gebhardt BM, O'Dorisio TM, O'Dorisio MS, Espenan GD, et al: Growing vascular endothelial cells express somatostatin subtype 2 receptors. $\mathbf{B r} \mathbf{J}$ Cancer 85:266-272, 2001

49. Woltering EA, Salvo VA, O'Dorisio TM, Lyons J III, Li G, Zhou Y, et al: Clinical value of monitoring plasma octreotide levels during chronic octreotide long-acting repeatable therapy in carcinoid patients. Pancreas 37:94-100, 2008

50. Yang C, Asthagiri AR, Iyer RR, Lu J, Xu DS, Ksendzovsky A, et al: Missense mutations in the NF2 gene result in the quantitative loss of merlin protein and minimally affect protein intrinsic function. Proc Natl Acad Sci U S A 108:49804985, 2011

\section{Disclosures}

The authors report no conflict of interest concerning the materials or methods used in this study or the findings specified in this paper.

\section{Author Contributions}

Conception and design: Graillon, Barlier. Acquisition of data: Graillon, Defilles, Mohamed. Analysis and interpretation of data: Graillon, Romano, Defilles, Saveanu. Critically revising the article: Romano, Saveanu, Chinot, Dufour, Barlier. Approved the final version of the manuscript on behalf of all authors: Graillon. Statistical analysis: Barlier. Administrative/technical/material support: Defilles, Mohamed, Figarella-Branger, Roche, Fuentes, Chinot, Dufour. Study supervision: Barlier.

\section{Supplemental Information \\ Online-Only Content}

Supplemental material is available with the online version of the article.

Supplementary Materials. https://thejns.org/doi/suppl/10.3171/ 2016.8.JNS16995.

\section{Correspondence}

Thomas Graillon, Department of Neurosurgery, Hopital La Timone, AP-HM, 264 rue Saint-Pierre, 13005 Marseille, France. email: thomas.graillon@ap-hm.fr. 